\title{
Esophageal anisakiasis observed using magnifying endoscopy with narrow-band imaging
}

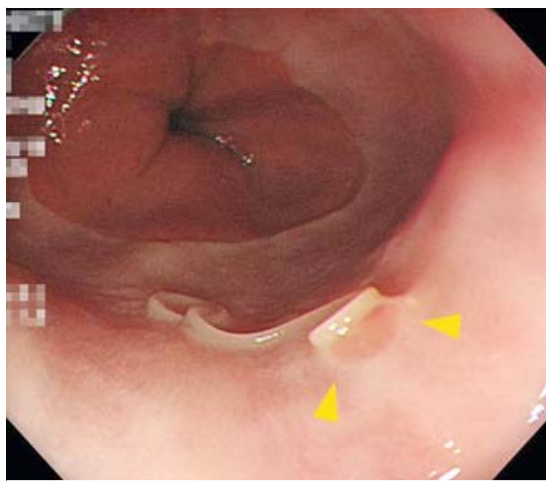

- Fig. 1 Esophagogastroduodenoscopy image showing an Anisakis larva invading the mucosa of the distal esophagus. At the invading site, a granulomatous reddish nodule approximately $2 \mathrm{~mm}$ in diameter is observed (arrowheads).

A 31-year-old man presented with a feeling of compression and intermittent pain in the epigastrium. He had eaten sliced raw fish (sashimi) for dinner at $10 \mathrm{pm}$ on the previous night and developed epigastric symptoms 2 hours thereafter. Physical examination revealed no tenderness or rebound tenderness in the epigastrium; his vital signs and laboratory parameters were normal. He reported a history of similar epigastric symptoms when he had had gastric anisakiasis; therefore, esophagogastroduodenoscopy (EGD) was conducted. This revealed an Anisakis larva invading the mucosa of the distal esophagus, where a granulomatous reddish nodule approximately 2 $\mathrm{mm}$ in diameter was observed ( $\mathbf{F i g} \mathbf{1}$ ). Magnifying endoscopy with narrow-band imaging (NBI) showed a rather flattened, smooth, and brownish nodule without vascular structure or surface pattern ( Fig.2a). Closer view of the larva revealed a small whitish elongated spot (the ventricle, an organ distally adjacent to the esophagus of Anisakis larva), which is seen more clearly than with conventional white-light endoscopic observation ( $\triangleright$ Fig. $\mathbf{2}$ b). After removing the parasite using biopsy forceps ( $\triangleright$ Video 1 ), his

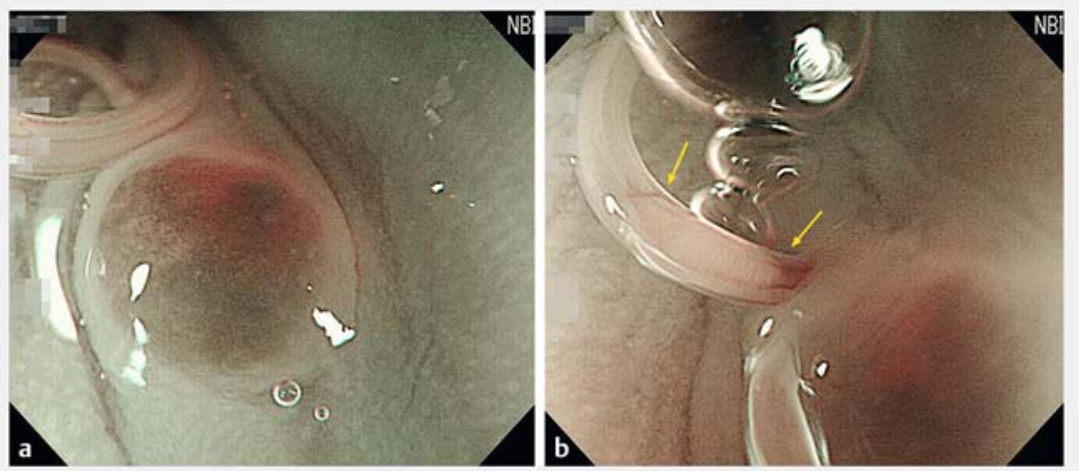

- Fig. 2 Magnifying endoscopy with narrow-band imaging showing: a a nodule that is round, rather flattened, and smooth, with neither vascular structure nor surface pattern of the brownish lesion; b on closer view of the Anisakis larva, a small whitish elongated spot (arrows) that is seen more clearly than on conventional white-light endoscopic observation (the whitish spot corresponds to the ventricle that is an organ distally adjacent to the esophagus of Anisakis larva).

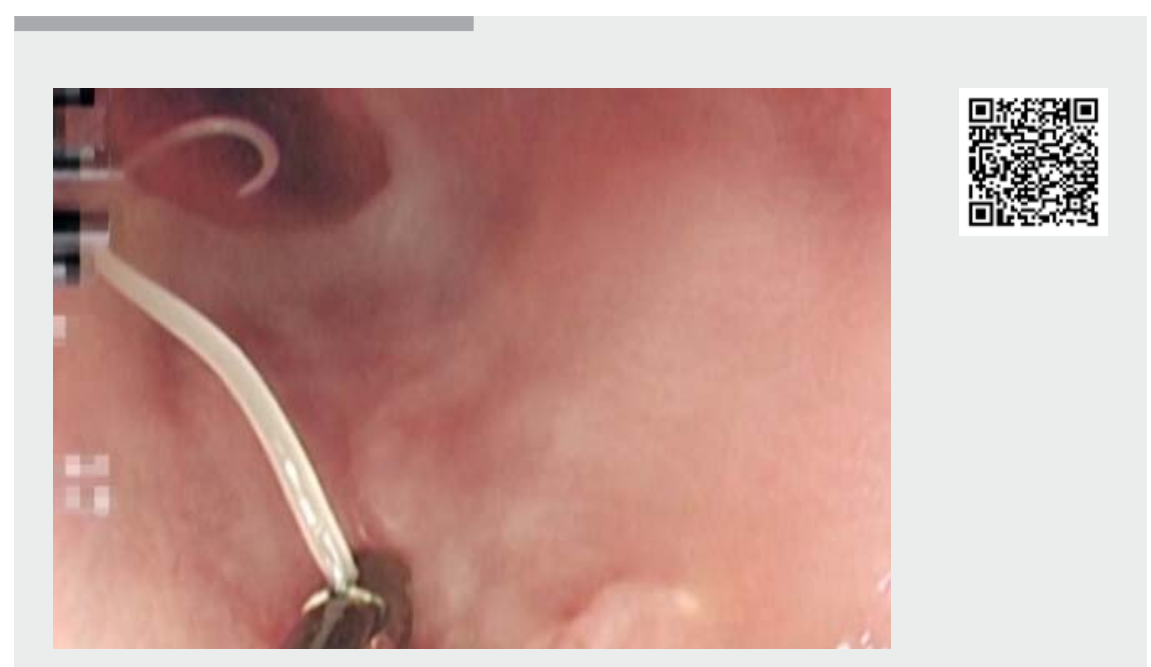

$\checkmark$ Video 1 Endoscopic observation of an Anisakis larva invading the esophageal mucosa using conventional white-light imaging and magnifying endoscopy with narrow-band imaging; thereafter, endoscopic removal of the larva is performed with biopsy forceps.

symptoms reduced immediately. At the 1-month follow-up EGD, the nodule had disappeared.

Anisakis infection most commonly affects the stomach and the small intestine [1]. Anisakiasis confined to the esophagus is very rare; only four cases have been reported thus far in the English literature [2-5]. To our knowledge, this is the first case report that showed a nodular lesion of esophageal mucosa penetrated by an Anisakis larva, although it is well known that gastric anisakiasis may cause a tumor-like nodule or mass (also called 
"vanishing tumor"). When gastrointestinal symptoms that occur after a history of consumption of raw or undercooked fish or squid suggest Anisakis infection, not only the stomach and the duodenum but also the esophagus should be thoroughly examined endoscopically. A study of further cases is needed to clarify whether the nodular lesion, as seen in our case, is common in esophageal anisakiasis.

Endoscopy_UCTN_Code_CCL_1AB_2AG_3AD

\section{Competing interests}

The authors declare that they have no conflict of interest.

The authors

Tomohiko Mannami' ${ }^{1}$, Nobukiyo Fujiwara², Genyo Ikeda ${ }^{2}$, Toshiyuki Wakatsuki ${ }^{1}$, Yasushi Fukumoto $^{1}$, Shin'ichi Furutachi ${ }^{1}$, Shin'ichi Shimizu ${ }^{1}$

1 Department of Gastroenterology, National Hospital Organization Okayama Medical Center, Okayama, Japan

2 Department of Internal Medicine, Chugoku Central Hospital, Fukuyama, Japan
Corresponding author

Tomohiko Mannami, MD

Department of Gastroenterology, National Hospital Organization Okayama Medical Center, 1711-1 Tamasu, Kita-Ku, Okayama 701-1192, Japan

Fax: +81-86-2949255

tmannami-gi@umin.ac.jp

\section{References}

[1] Hochberg NS, Hamer DH. Anisakidosis: Perils of the deep. Clin Infect Dis 2010; 51: 806-812

[2] Urita Y, Nishino M, Koyama $\mathrm{H}$ et al. Esophageal anisakiasis accompanied by reflux esophagitis. Intern Med 1997; 36: 890-893

[3] Muguruma N, Okamura S, Okahisa T et al. Anisakis larva involving the esophageal mucosa. Gastrointest Endosc 1999; 49: 653-654

[4] Uehara A, Okumura T. Esophageal anisakiasis mimicking gastroesophageal reflux disease. Am J Gastroenterol 2017; 112: 532

[5] Ikegami K, Hirose Y, Yoneyama O. An unusual cause of severe epigastric pain. Gastroenterology 2018; 154: e7-e8
Bibliography

Endoscopy 2021; 53: E83-E84

DOI 10.1055/a-1195-2273

ISSN 0013-726X

published online 26.6.2020

(c) 2020. Thieme. All rights reserved.

Georg Thieme Verlag KG, Rüdigerstraße 14,

70469 Stuttgart, Germany

\section{ENDOSCOPY E-VIDEOS \\ https://eref.thieme.de/e-videos}

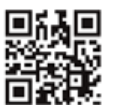

Endoscopy E-Videos is a free access online section, reporting on interesting cases and new techniques in gastroenterological endoscopy. All papers include a high quality video and all contributions are freely accessible online.

This section has its own submission website at

https://mc.manuscriptcentral.com/e-videos 